Document downloaded from:

http://hdl.handle.net/10251/78706

This paper must be cited as:

Jesús Benajes; Martín Díaz, J.; García Martínez, A.; Villalta Lara, D.; Warey, A.; Doménech Llopis, V.; Vassallo, AL.... (2015). An Investigation of Radiation Heat Transfer in a Light-Duty Diesel Engine. SAE International Journal of Engines. 8(5):1-14. doi:10.4271/2015-24-2443.

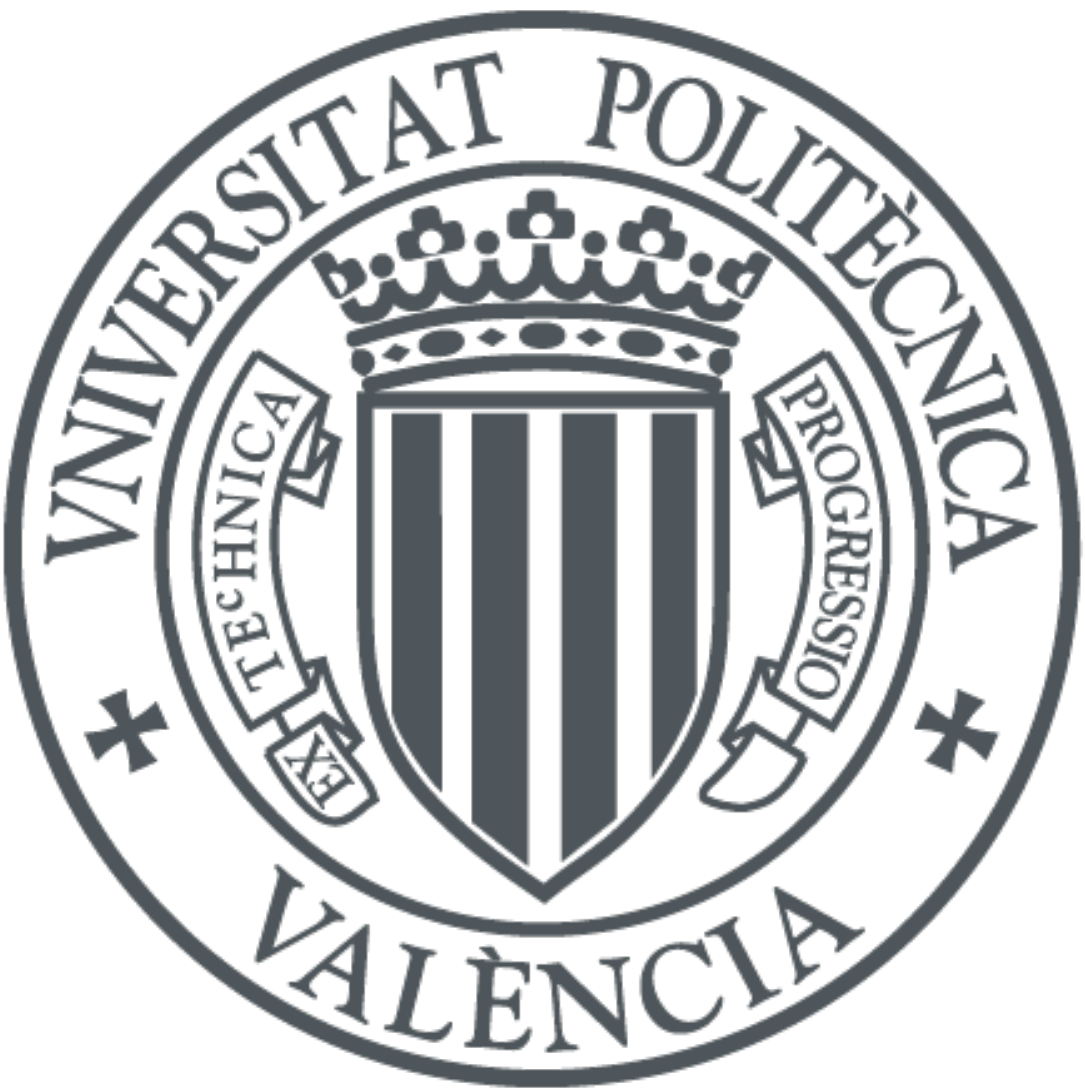

The final publication is available at

http://dx.doi. org/10.4271/2015-24-2443

Copyright SAE International

Additional Information 


\title{
An Investigation of Radiation Heat Transfer in a Light-Duty Diesel Engine
}

\author{
Jesús Benajes, Jaime Martín, Antonio García, David Villalta \\ Universitat Politècnica de València \\ Alok Warey and Vicent Domenech \\ General Motors Global R \& D \\ Alberto Vassallo \\ GM Powertrain
}

\begin{abstract}
$\underline{\text { ABSTRACT }}$
In the last two decades engine research has been mainly focused on reducing pollutant emissions. This fact together with growing awareness about the impacts of climate change are leading to an increase in the importance of thermal efficiency over other criteria in the design of internal combustion engines (ICE). In this framework, the heat transfer to the combustion chamber walls can be considered as one of the main sources of indicated efficiency diminution. In particular, in modern direct-injection diesel engines, the radiation emission from soot particles can constitute a significant component of the efficiency losses. Thus, the main of objective of the current research was to evaluate the amount of energy lost to soot radiation relative to the input fuel chemical energy during the combustion event under several representative engine loads and speeds. Moreover, the current research characterized the impact of different engine operating conditions on radiation heat transfer. For this purpose, a combination of theoretical and experimental tools were used. In particular, soot radiation was quantified with a sensor that uses two-color thermometry along with its corresponding simplified radiation model. Experiments were conducted using a 4-cylinder direct-injection light-duty diesel engine fully instrumented with thermocouples. The goal was to calculate the energy balance of the input fuel chemical energy. Results provide a characterization of radiation heat transfer for different engine loads and speeds as well as radiation trends for different engine operating conditions.
\end{abstract}

\section{INTRODUCTION}

The increasing concern due to the effect of GHG emissions is pushing the researchers and manufacturers to look for more efficient engines with lower fuel consumption and $\mathrm{CO}_{2}$ emissions. Thus, different strategies are proposed to achieve these objectives; thermal management improvement [1, 2], indicated cycle optimization $[3,4]$, in- cylinder heat transfer (HT) reduction $[5,6]$, reduction of friction and auxiliaries losses $[7,8]$ or engine downsizing [9] among others. In the present work, the research effort has been focused on improving knowledge of in-cylinder heat transfer.

Combustion process in Direct Injection (DI) diesel engines includes different physical and chemical processes. During the turbulent diffusion flame, an important balance between soot formation and oxidation occurs in the spray. During oxidation process, the in-cylinder soot emission is luminous and generates an important source of radiant energy [10]. Carbon dioxide and water vapor molecules also emit radiation, however it is concentrated in a narrow spectral bands and its magnitude is assumed much smaller than soot particles. Moreover, radiation may also be emitted by many intermediate species formed during the combustion process, but since their concentration levels are small, their effect on radiation heat transfer is less important as is described in [11]. Thus, soot radiation can be considered a significant source of the efficiency losses in modern diesel engines [12]. In this sense, there are different studies in the literature which quantify the amount of fuel chemical energy lost by soot radiation [12]. Depending on soot conditions, studies provide very different results. From $0.5-1 \%$ [13] up to $5-10 \%[10,14]$ of the total chemical energy released during combustion process can be considered as radiant losses. Not only the amount of radiant fraction is a controversy, but also the contribution of radiation to the total heat transfer varies significantly as well from $11 \%$ up to $40 \%$ [10]. The significant differences between authors are directly related with the uniqueness of the radiant emission in each combustion system considering particular engine geometry and the operating conditions tested. Therefore, it could be stated that the relationship between all these combustion and engine parameters and its radiant emission is not fully understood currently.

The two-color pyrometry method has been used to determine radiation heat transfer along with the in-cylinder temperature and the soot volume fraction (using KL factor) from diesel engine flames $[15,16]$. A detailed description of the two-color pyrometry method can be found in [17]. Thus, pyrometry can be performed by using two different strategies; two dimensionally using a 
fast sampling high-speed camera $[18,19]$ or zero dimensionally based on a collecting lens and an optical fiber in combination with a photo diode [12]. The first method provides spatial and temporal resolution of soot temperature and KL. Therefore, radiant emission can be calculated through this technique. This method is applied in particular to vessels, which can reproduce diesel engine like environment or in optical engines. The second method is applied in production engine experiments where the room for optical access to the combustion chamber is limited. The recorded signal in this case represents the spatially integrated information of a three dimensional complex phenomena which is characterized by significant gradients of spatial equivalence ratios and temperature along with the combination of reactive and nonreactive zones as well as different absorption coefficients and soot particle densities along the line of sight. [12].

Independent of the measurement technique method, there always exists some uncertainty of fouling impact from incylinder soot in the optical device or from occlusion of the field of view by geometric factors of the measurement system. Consequently, more research and efforts are needed in this field.

The main objective of this work was to evaluate the amount of energy to soot radiation relative to the input fuel chemical energy during the combustion event under different operating conditions in a completely controlled ambient provided by an optical engine. Under these simplified conditions, two-color method was applied by using high speed imaging pyrometer with cameras (two dimensional results) and optoelectronic pyrometer (zero dimensional results). Once a detailed comparison between both strategies was performed, a twocolor thermometry sensor was used to characterize radiant energy in a fully instrumented production 4-cylinder directinjection light-duty diesel engine under several representative engine loads and speeds. The final goal was to calculate the energy balance of the input fuel chemical energy. Results provide radiation heat transfer characterization for different engine loads and speeds as well as radiation trends.

\section{EXPERIMENTAL SET-UP AND PROCESSING TOOLS}

\section{Experimental test benches}

Two different test benches have been used to perform this work, an optically accessible single cylinder engine and a multi-cylinder engine.

\section{Optically accessible engine}

This facility is based on a 2-stroke single cylinder direct injection diesel engine (Jenbach JW 50), further information can be found in [20]. The engine has three liter displacement with $150 \mathrm{~mm}$ of bore and $170 \mathrm{~mm}$ of stroke. It is motored at low engine speed (500 rpm). Intake and exhaust are handled by ports on the liner and the cylinder head is specially designed to provide optical access to the combustion chamber. A cylindrical combustion chamber was designed to avoid the spray wall impingement. The chamber has an upper port where the injector is mounted and four lateral accesses. One of these accesses is used for placing a pressure transducer whereas the other three are equipped with oval-shaped quartz windows, $88 \mathrm{~mm}$ length, $37 \mathrm{~mm}$ width and $28 \mathrm{~mm}$ thickness as it is shown in figure 1 . The cylinder head and the engine temperature was controlled by means of coolant recirculation. Its temperature was set to $353 \mathrm{~K}$, to guarantee a good lubricant oil performance. a)

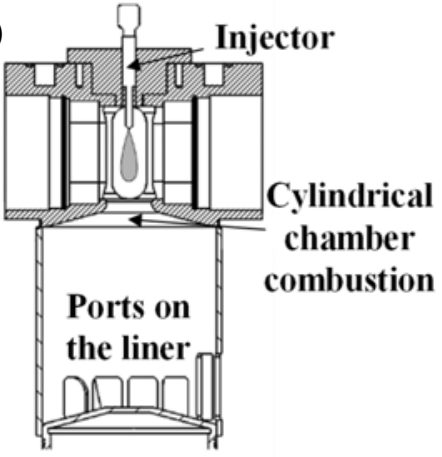

b)

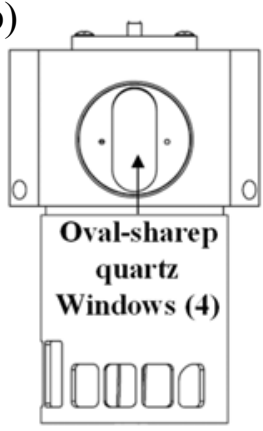

Figure 1. Scheme of the cylinder head and the liner arrangement. a) Front view, b) Side view

In order to keep in-cylinder conditions constant (pressure and temperature), the engine was operated under skip-fired mode. One injection event takes place every 30 cycles, which guarantees that in-cylinder conditions are not influenced by residual gases from previous cycle.

A common-rail Bosch injection system was used, together with a piezoelectric injector and a single-hole $140 \mu \mathrm{m}$ outlet diameter nozzle. The injector hole was $1 \mathrm{~mm}$ long with conical shape $\left(\mathrm{K}_{\mathrm{s}}\right.$ factor of 1.5$)$. The injected mass was relatively small compared to the volume of air utilized. Hence it can be assumed that the thermodynamic conditions inside the combustion chamber were barely affected by the fuel evaporation. Due to the low injection frequency used during tests, the temperature of the injected fuel can be considered constant during the tests.

\section{Light Duty Diesel engine}

A production-type GM 1.9L Diesel engine was used for the second part of the study. The 4-cylinder engine uses a Common-Rail fuel injection system, variable geometry turbocharger (VGT), an exhaust gas recirculation system and an intake throttle valve. The engine has four valves per cylinder, centrally located injectors, and a re-entrant type combustion chamber. The swirl number is variable from 1.4 up to 2.9 and can be adjusted by a dedicated valve. All 
relevant engine data as well as injection system are given in table 1. This engine was set up with EURO IV calibration.

Table 1. Engine and injection system specifications

\begin{tabular}{|l|l|}
\hline Engine Type & $\begin{array}{l}\text { DI, 4-cylinder,charged,4- } \\
\text { stroke }\end{array}$ \\
\hline Displaced volume & $1900 \mathrm{cc}$ \\
\hline Stroke & $90.4 \mathrm{~mm}$ \\
\hline Bore & $82 \mathrm{~mm}$ \\
\hline Combustion Chamber & Re-entrant type \\
\hline Compression ratio & $17.5: 1$ \\
\hline Max. Power [kW] & 110 @4000rpm \\
\hline Max. Torque [Nm/min $\left.{ }^{-1}\right]$ & $320 / 2000-2750$ \\
\hline Injection System & $\begin{array}{l}\text { Bosch Common Rail } \\
(\text { solenoid) }\end{array}$ \\
\hline Max. Rail Pressure [bar] & 1600 \\
\hline Nozzle hole diameter $[\mathrm{mm}]$ & 0.141 \\
\hline Injector Nozzle Holes & 7 \\
\hline $\begin{array}{l}\text { Hydraulic flow rate }\left[\mathrm{cm}^{3}\right. \\
\text { (30s) at } 100 \text { bar] }\end{array}$ & 440 \\
\hline
\end{tabular}

The engine was directly coupled to an electric dynamometer that allows controlling the engine speed and load. The installation also included a complete instrumentation to measure different fluid temperatures and mass flows. The list of the relevant instrumentation is depicted in table 2 .

Table 2. Test cell instrumentation

\begin{tabular}{|l|l|l|}
\hline Variables to measure & Sensors & Range \\
\hline $\begin{array}{l}\text { Temperature of liquids } \\
\text { (coolant, oil, cooling } \\
\text { water at exchangers...) }\end{array}$ & $\begin{array}{l}\text { Thermoresistances } \\
(\mathrm{PT} 100)\end{array}$ & $-30-350{ }^{\circ} \mathrm{C}$ \\
\hline $\begin{array}{l}\text { Temperature of gases } \\
\text { (inlet and exhaust lines, } \\
\text { EGR...) }\end{array}$ & $\begin{array}{l}\text { K-type } \\
\text { Thermocouples }\end{array}$ & $-200-1250{ }^{\circ} \mathrm{C}$ \\
\hline Fuel mass flow & AVL 733s.18 & $0-41.67 \mathrm{~g} / \mathrm{s}$ \\
\hline Air mass flow & $\begin{array}{l}\text { AVL Flowsonix } \\
\text { Air }\end{array}$ & $0-1400 \mathrm{~kg} / \mathrm{h}$ \\
\hline Coolant Flow & DN25 Flow meter & $8.8-350 \mathrm{l} / \mathrm{min}$ \\
\hline Torque & Dynamometer & $0-500 \mathrm{Nm}$ \\
\hline In-cylinder pressure & Kistler 6125C10 & $0-300 \mathrm{bar}$. \\
\hline
\end{tabular}

A combination of thermocouples and resistance temperature detectors (PT100) was selected (taking into account the expected temperature variation) to measure liquid and gas temperatures.

The in-cylinder pressure was measured for each cylinder with Kistler 6125C10 glow-plug piezoelectric transducers and Page 3 of 17
Kistler 4603B10 charge amplifiers. A crank angle increment of $0.5^{\circ}$ was used for the in-cylinder pressure acquisition, which was performed using DRIVVEN [21].

The mean variables were acquired at a low sample frequency of $100 \mathrm{~Hz}$ using SAMARUC, a CMT-developed test system that collects the signals of different sensors and controls the electric dynamometer [22].

\section{Theoretical Tools}

The combustion analysis was performed by means of CALMEC, a CMT-developed tool as described in [23]. Its main assumptions are the following:

- The chamber is considered an open system to account for the fuel injection and blow-by leakage.

- Combustion chamber pressure and temperature are assumed to be spatially uniform.

- Three species (air, fuel vapor and stoichiometric combustion products) are considered [24].

Ideal gas law is used to calculate gas temperature.

- A filling and emptying model is used to calculate the trapped mass [25].

- The specific heat of the gas depends on both temperature and composition [26].

- Blow-by model is based on the evolution of the gas in an isentropic nozzle [24].

- The chamber volume deformation due to pressure and inertia is calculated by means of a simple deformation model [23]. - The heat transfer coefficient in the chamber walls is calculated with a modified Woschni-like model [27]:

$$
\begin{gathered}
h=C D^{-0.2} p^{0.8} T^{-053}\left[C_{W 1} c_{m}+C_{W 2} c_{u}+C_{2} \frac{V_{d} T_{I V C}}{V_{I V C} p_{I V C}}(p-\right. \\
\left.\left.p_{0}\right)\right]^{0.8}(1)
\end{gathered}
$$

Where $\mathrm{C}$ and $\mathrm{C}_{2}$ are constants whose values are 0.12 and $0.001, \mathrm{c}_{\mathrm{m}}$ is the mean piston speed, $\mathrm{c}_{\mathrm{u}}$ is the instantaneous tangential velocity of the gas in the chamber that was adjusted using CFD calculations [27], $\mathrm{p}_{0}$ is the pressure during motoring conditions assuming a polytrophic evolution, and finally $\mathrm{C}_{\mathrm{W} 1}$ and $\mathrm{C}_{\mathrm{W} 2}$ are constants, whose values are adjusted for each engine by means of a combination of experimental and modelling methodology [28].

CALMEC solves the first law of thermodynamics for an open system to obtain the RoHR [23]:

$$
\begin{gathered}
R o H R=m c_{v} \frac{d T}{d \alpha}+\frac{d Q}{d \alpha}+p \frac{d V}{d \alpha}-\left(h_{f, i n j}-u_{f, g}\right) \frac{d m_{f, e v}}{d \alpha}+ \\
R T \frac{d m_{b b}}{d \alpha} \quad \text { (2) }
\end{gathered}
$$

Where $\alpha$ is the crank angle degree, $\mathrm{m}, \mathrm{dT}$ and $\mathrm{dQ}$ are the instantaneous mass in the chamber, gas temperature variation and instantaneous heat transfer to the chamber walls respectively, $c_{v}$ is the specific heat which depends on the instantaneous temperature and composition, $\mathrm{dm}_{\mathrm{f}, \mathrm{ev}}$ is the 
variation of injected mass, $h_{f, i n j}$ and $u_{f, g}$ are the injected fuel enthalpy and internal energy of the evaporated fuel, $\mathrm{R}$ is the gas constant and $\mathrm{dm}_{\mathrm{bb}}$ is the variation of blow-by leakage. Additionally, the heat transfer to the chamber wall Q together with a lumped conductance model allows for accurate calculation of the RoHR.

\section{METHODOLOGY}

\section{Two color method}

This method was applied to two different optical setups - High Speed imaging and an Optoelectronic Pyrometer. Two color pyrometry is an optical thermometry technique that makes use of the presence of radiating soot inside the flame. The intensity of radiation emitted by soot particles $\left(\mathrm{I}_{\text {soot }}\right)$ is proportional to the radiation emitted by a black body at the same temperature $(\mathrm{T})$. This proportionality is determined by the emissivity of the particles, which can be expressed in terms of soot concentration, working wavelength $(\lambda)$ and a constant parameter $(\alpha)$ [29]. Therefore, $I_{\text {soot }}$ can be expressed as the following equation:

$$
I_{\text {soot }}(\lambda, T, K L)=\varepsilon_{\lambda} I_{b, \lambda}=\left[1-\exp \left(-\frac{K L_{2 C}}{\lambda^{\alpha}}\right)\right] \frac{1}{\lambda^{5}} \frac{c_{1}}{\left[\exp \left(\frac{c_{2}}{\lambda T}\right)-1\right]}
$$

Where $\mathrm{c}_{1}=1.1910439 \times 10^{-16} \mathrm{Wm}^{2} \mathrm{sr}^{-1}$ and $\mathrm{c}_{2}=1.4388 \times 10^{-}$ ${ }^{2} \mathrm{mK}$. Zhao et al. [30] reported that $\alpha$ values are less dependent on the wavelength in the visible range than in the infrared.

In this regard, 550 and $650 \mathrm{~nm}$ with $\pm 10 \mathrm{~nm}$ FWHM have been chosen when the method is used with two High-Speed CMOS cameras and 600 and $950 \mathrm{~nm}$ with $\pm 50 \mathrm{~nm}$ FWHM are used when the method is applied using the Optoelectronic Pyrometer. In this study $\alpha$ was assumed to be 1.39 , which is a commonly used for most of fuels [31]. The dependence of the emissivity on the soot amount within the optical path is usually expressed in terms of $\mathrm{KL}_{2 \mathrm{C}}=\mathrm{k}_{\text {soot }} \mathrm{L}$. This variable accounts for the total contribution of the soot along the optical path, independent of the soot distribution or geometrical size.

Two high speed cameras with two CMOS sensors were employed to measure soot radiation. The signal "S" depends on the detector spectral response, the radiation itself, the area A of the sooting flame within the field of view of the detector and the solid angle $\Omega$ subtended by the detector. Several simplifications can be applied [29], and a final expression (equation (4)) is obtained for each wavelength:

$$
S_{\lambda}=C_{\lambda} I_{\text {soot }}(\lambda, T, K L)
$$

Where $\mathrm{C}_{\lambda}$ is a constant that takes into account $\mathrm{A}, \Omega$ and $\lambda$. This parameter has to be calculated by means a radiance calibration procedure. For this purpose, calibration curves were obtained by means of a previously calibrated light source, as it is described by Payri et al. [29]. The slope of Page 4 of 17 these curves is the transformation factor $\left(\mathrm{C}_{\lambda}\right)$ presented in equation (4).

\section{Optical set-up}

\section{$\underline{\text { High Speed Imaging Pyrometer }}$}

The light emitted by the flame pass through a beam splitter which transmits and reflects $50 \%$ of the soot radiation to each of the two High-Speed CMOS cameras employed: a Phantom V12 for $650 \mathrm{~nm}$ and Photron SA5 for $550 \mathrm{~nm}$. Both cameras were equipped with a $100 \mathrm{~mm}$ focal length and $\mathrm{f} / 2$ lens. In order to ensure frame-to-frame synchronization, both cameras were connected in a Master/Slave mode. They were set to record at $15000 \mathrm{fps}$, with 5 to $8 \mu$ s exposure time for $650 \mathrm{~nm}$ and 8 to $12 \mu \mathrm{s}$ for the $550 \mathrm{~nm}$, depending on test conditions. A scheme of the set-up is shown in figure 2.

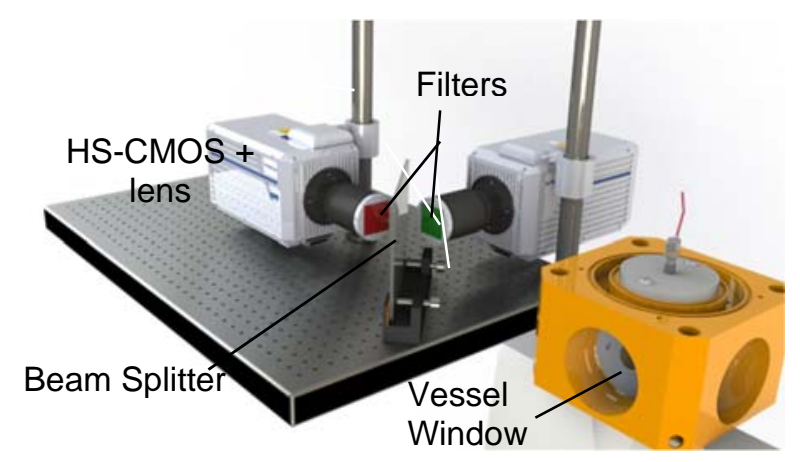

Figure 2: High Speed Imaging pyrometer Set-up

A spatial transformation is required to match both images pixel by pixel. A spatial transformation matrix is calculated, considering translation, rotation and scaling. For both images, background segmentation is also applied. A threshold value is obtained, considering a percentage of the total dynamic range of each image. The value of this percentage was set to $5 \%$ for all the tests performed, which has shown good accuracy on the flame boundary detection for all the tests. Only pixels with an intensity greater than the above mentioned $5 \%$ are considered part of the flame. Once both images are coupled, equation (3) was applied for each wavelength and $\mathrm{KL}_{2 \mathrm{C}}$ and temperature can be obtained for each instant with a resolution of two spatial dimensions. In figure 3 , an example of the application is shown. 


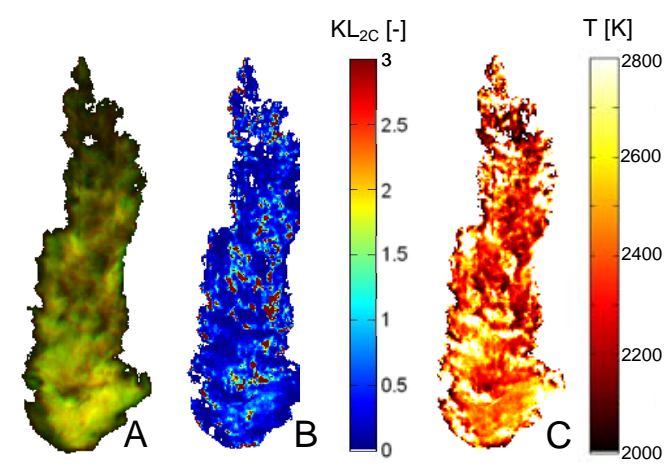

Figure 3. Composition of instantaneous soot natural luminosity at 550 and $650 \mathrm{~nm}(A)$ and the corresponding $\mathrm{KL}$ (B) and Temperature (C) distributions. Data was taken for $30 \%$ Decane -70\% Hexadecane, at $\rho_{c}=23.4 \mathrm{~kg} / \mathrm{m}^{3}, \mathrm{~T}_{c}=800$ $K$ and $P_{i n j}=50 \mathrm{MPa}$.

\section{Optoelectronic Pyrometer}

The in-cylinder soot radiation measurements were also performed with an optoelectronic signal converter with a selection of photodiodes and narrow band optical filters adapted to specific applications for combustion engine flame and radiation measurement. This light probe has been developed by AVL and is known as VisioFEM. A sapphire lens at the tip of the probe captures the light from the combustion chamber with a view angle of $90^{\circ}$. The soot radiation is conducted through optical fibers and split to two filters at wavelengths of 600 and $950 \mathrm{~nm}$. Then, the photodiodes convert the intensity to a voltage signal. The signals from the photodiodes are amplified and recorded every $0.5^{\circ} \mathrm{CAD}$. Signal conversion and signal conditioning ensures highest possible linearity of input radiation intensity to output signal voltage. The Optoelectronic raw signals and the absolute light intensities are linked by a calibration of the whole measurement chain using a halogen lamp, which provides a homogenously illuminated surrounding. A particular testing methodology is recommended by AVL with the aim of preventing the undesired errors in transmission due to soot deposits during a measurement campaign. [32]. A schematic of the signal path from the flame to the data acquisition device is presented in figure 4.

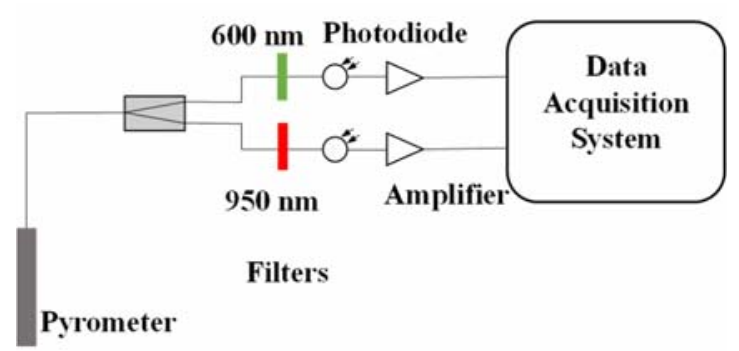

Figure 4. Signal path from flame to data acquisition device
Once both voltage signals are recorded, spectral intensity is obtained considering gain, transmission and sensitivity. Thus, once the voltage signal are converted, equation (3) is applied for each wavelength and $\mathrm{KL}_{2 \mathrm{C}}$ and temperature can be obtained at each instant. It is interesting to remark that with the Optoelectronic probe only temporal resolution is obtained for the soot temperature and KL results.

For the sake of clarity, figure 5 presents the optical set up when the optoelectronic pyrometer is used in both experimental engines.

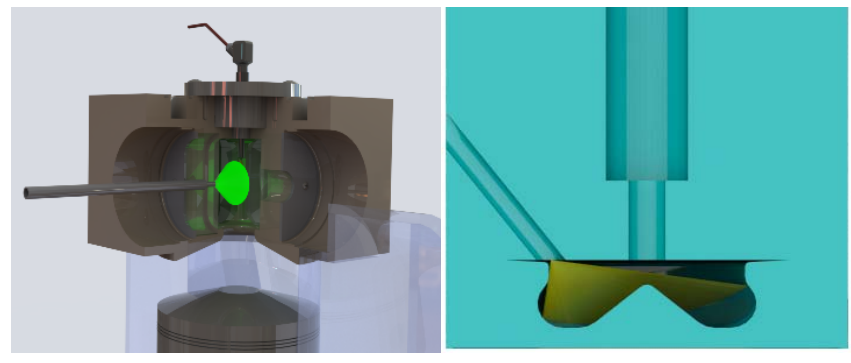

Figure 5 Optoelectronic pyrometer set up Left) Optical accessible engine configuration and Right) Light duty engine configuration

\section{Operating conditions}

\section{Optically accessible engine}

The test matrix includes eight different engine operating conditions (table 3 ). The injected fuel mass has been obtained with an injection rate meter. To determine the intake pressures and temperatures required for the test plan, an accurate characterization of the engine has been performed, covering its full operation range. In-cylinder thermodynamic conditions have been calculated from measured pressure, using first-law thermodynamic analysis. This analysis takes into account blow-by, heat losses and mechanical deformations. The trapped mass is estimated using intake temperature and volume at EVC. Instantaneous in-cylinder temperature evolution during the cycle is calculated using the equation of state and correcting the trapped mass with blow-by estimations. Mechanical deformations can lead to a correction on instantaneous geometric volume; however, in this specific engine they have been neglected. Figure 6 shows an example of the resulting pressure and density evolution during the injection. 
Table 3. Experimental conditions optical engine

\begin{tabular}{|c|c|c|c|c|}
\hline $\begin{array}{c}\text { TDC } \\
\text { Temp. } \\
{[\mathbf{K}]}\end{array}$ & $\begin{array}{c}\text { TDC } \\
\text { Density } \\
{\left[\mathbf{k g} / \mathbf{m}^{3}\right]}\end{array}$ & $\begin{array}{c}\text { Injection } \\
\text { Pressure } \\
{[\mathbf{b a r}]}\end{array}$ & $\begin{array}{c}\text { Injected } \\
\text { fuel } \\
\text { mass } \\
{[\mathbf{m g} / \mathbf{s t k}]}\end{array}$ & $\begin{array}{c}\text { Equivalence } \\
\text { ratio [-] }\end{array}$ \\
\hline \multirow{3}{*}{800} & 23.4 & $\begin{array}{c}500 / 1000 \\
/ 1500\end{array}$ & $\begin{array}{c}13.4 / 20.3 \\
/ 25.4\end{array}$ & $\begin{array}{c}0.05 / 0.07 / \\
0.09\end{array}$ \\
\cline { 2 - 5 } & 18.9 & 1000 & 20.1 & 0.08 \\
\hline \multirow{3}{*}{900} & 23.4 & $\begin{array}{c}500 / 1000 \\
/ 1500\end{array}$ & $\begin{array}{c}13.4 / 20.3 \\
/ 25.4\end{array}$ & $\begin{array}{c}0.05 / 0.07 / \\
0.09\end{array}$ \\
\cline { 2 - 5 } & 18.9 & 1000 & 20.1 & 0.08 \\
\hline
\end{tabular}

Energizing time was set to $2 \mathrm{~ms}$ for all conditions, which results in an approximate $4.5 \mathrm{~ms}$ hydraulic injection duration. The injector was triggered at $-6.05^{\circ}$ aTDC (SoE) and the injection starts at $-5.9^{\circ}$ aTDC (SoI), to minimize variations of in-cylinder conditions during injection event. Each test was repeated 20 times to reduce measurement uncertainties due to engine operating variability as well as to improve signal-tonoise ratio.

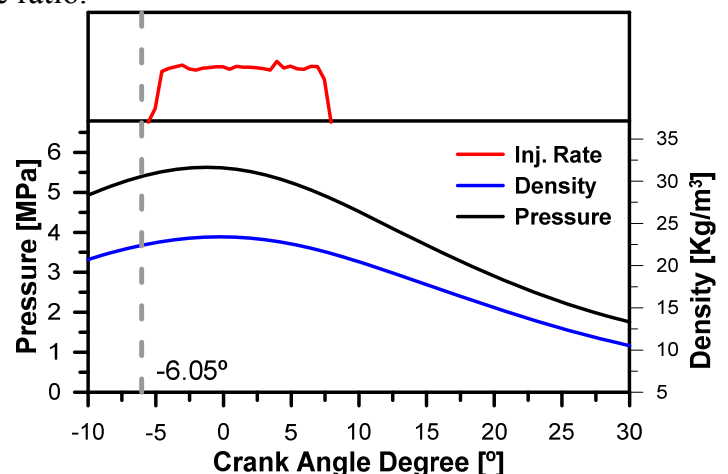

Figure 6. Thermodynamic in-cylinder conditions along engine cycle under motored conditions. Injection rate is just shown to clarify the timing and duration of the injection event.

In this work, one blend using two different fuels, n-decane and n-hexadecane, have been employed. In fact, the fuel used is a blend of both single component fuels at a $30 \%-70 \%$ volume fraction. They have been chosen due to their simplicity (pure fuels) and similarity with diesel fuel in terms of physical and chemical properties. Table 4 shows main fuel properties.

Table 4. Fuel properties at $1 \mathrm{~atm}$ and $100^{\circ} \mathrm{C}$

\begin{tabular}{|c|c|c|c|}
\hline Fuel & $\begin{array}{c}\text { Density @ } \\
\mathbf{3 7 3 ~ K} \\
{\left[\mathbf{k g} / \mathbf{m}^{3}\right]}\end{array}$ & $\begin{array}{c}\text { Dynamic } \\
\text { Viscosity @ } \\
\mathbf{3 7 3 ~ K} \\
{[\mathbf{m P a} \mathbf{s}]}\end{array}$ & $\begin{array}{c}\text { Vapor } \\
\text { Pressure } \\
\text { at 373 K } \\
{[\mathbf{k P a}]}\end{array}$ \\
\hline $\begin{array}{c}30 \% \mathrm{C}_{10} \mathrm{H}_{22}- \\
70 \% \mathrm{C}_{16} \mathrm{H}_{34}\end{array}$ & 703.7 & 0.667 & 7.72 \\
\hline
\end{tabular}

\section{Light Duty Diesel engine}

The engine was operated at different engine speeds and loads. In particular, six operating points at steady-state were selected with the aim of cover a wide range of soot emissions and different radiation heat rejection. For that purpose, different injection strategies (SoIs and Injection pressure), EGR levels, intake and exhaust pressures were tested. 100 engine cycles were recorded for each setting.

Table 5 presents the matrix for operating conditions used in this study.

Table 5. 4-cylinder engine operating conditions

\begin{tabular}{|l|c|c|c|c|c|c|}
\hline $\begin{array}{l}\text { Operation } \\
\text { condition }\end{array}$ & $\begin{array}{c}1500 \\
@ 8\end{array}$ & $\begin{array}{c}1500 \\
\text { @ } 14\end{array}$ & $\begin{array}{c}2000 \\
@ 2\end{array}$ & $\begin{array}{c}2000 \\
\text { @ } 5\end{array}$ & $\begin{array}{c}2500 \\
@ 14\end{array}$ & $\begin{array}{c}3000 \\
@ 14\end{array}$ \\
\hline Torque (Nm) & 122 & 214 & 31 & 76 & 216 & 214 \\
\hline Load (\%) & 48 & 84 & 10 & 24 & 68 & 69 \\
\hline $\begin{array}{l}\text { Engine speed } \\
\text { (RPM) }\end{array}$ & 1500 & 1500 & 2000 & 2000 & 2500 & 3000 \\
\hline $\begin{array}{l}\text { Injection } \\
\text { pressure (bar) }\end{array}$ & 729 & 1041 & 466 & 655 & 1430 & 1517 \\
\hline $\begin{array}{l}\text { Fuel Flow } \\
\text { (kg/min) }\end{array}$ & 0.07 & 0.13 & 0.035 & 0.065 & 0.196 & 0.229 \\
\hline SoE ('BTDC) & 3.033 & 4.008 & 2.104 & 2.630 & 8.675 & 11.51 \\
\hline $\mathrm{T}_{\text {in }}(\mathrm{K})$ & 302.2 & 302.7 & 303.0 & 303.0 & 303.2 & 303.6 \\
\hline $\mathrm{P}_{\text {in }}$ (bar) & 1.378 & 1.738 & 1.117 & 1.269 & 2.092 & 2.242 \\
\hline $\mathrm{P}_{\text {exh }(\text { bar) }}$ & 1.726 & 2.433 & 1.293 & 1.482 & 2.274 & 2.720 \\
\hline $\begin{array}{l}\text { Air Flow } \\
\text { (kg/min) }\end{array}$ & 1.81 & 2.29 & 1.06 & 1.73 & 4.60 & 6.07 \\
\hline EGR (\%) & 0 & 0 & 48 & 27 & 0 & 0 \\
\hline $\begin{array}{l}\text { Equivalence } \\
\text { ratio }\end{array}$ & 0.565 & 0.829 & 0.482 & 0.549 & 0.622 & 0.551 \\
\hline
\end{tabular}

Commercially available European diesel fuel was used in this part of the work. Table 6 shows the main characteristics of the fuel used.

Table 6. Fuel properties at $1 \mathrm{~atm}$ and $40^{\circ} \mathrm{C}$

\begin{tabular}{|c|c|c|}
\hline Fuel & $\begin{array}{c}\text { Density @ } \\
\mathbf{3 1 3} \mathbf{K} \\
{\left[\mathbf{k g} / \mathbf{m}^{\mathbf{3}}\right]}\end{array}$ & $\begin{array}{c}\text { Dynamic } \\
\text { Viscosity } @ \\
\mathbf{3 1 3} \mathbf{K} \\
{[\mathbf{c S t k}]}\end{array}$ \\
\hline Diesel & 820 & 2.38 \\
\hline
\end{tabular}




\section{RESULTS AND DISCUSSIONS}

This section presents the results obtained in the optically accessible engine together with those from the 4-cylinder light-duty diesel engine.

\section{Optical Engine Characterization of Radiation}

\section{In-cylinder spectral intensity, temperatures and optical thickness (KL) measurements}

The objective of this section is twofold. First, the effects of variations in different engine operating parameters on spectral intensity in a test rig with a completely controlled environment are presented. Second, some experiments were performed with the aim of evaluating the validation of the Optoelectronic Pyrometer (OP) versus a conventional optical set-up, High Speed Imaging Pyrometer (HSIP), in terms of KL and incylinder soot temperature. Then, an evaluation of the radiant fraction from the total energy supplied to the chamber is presented.

In figure 7 is shown temporal evolution of the spectral intensity $\left(\mathrm{I}_{\text {soot }}\right)$ measurements for both optical systems. In this work only values in the quasi steady state part of the diffusion combustion process are shown. Thus, results for three different injection pressures are presented $(500,1000$ and 1500 bar). Curves related to High Speed Imaging Pyrometer (HSIP) represent the average of 20 fired cycles together with their standard deviation at each data point. The wavelengths used in for this method are $550 \mathrm{~nm}$ and $650 \mathrm{~nm}$. Thus, an average image per instant with spatial resolution is obtained and later, a spatial average of the complete image in each instant is performed. In addition, the profiles related to the Optoelectronic Pyrometer (OP) are the average of the same 20 fired cycles at each data point. In these curves are also represented the standard deviation of measured points. The wavelengths used for this system are $600 \mathrm{~nm}$ and $950 \mathrm{~nm}$. It is interesting to underline that independently on the operating conditions, higher spectral intensity is obtained when higher wavelength filter is used.

Comparing results dispersion between both methods, a slightly greater standard deviation is obtained with the Optoelectronic Pyrometer. Nevertheless, consistent results are obtained from the two different optical setups.

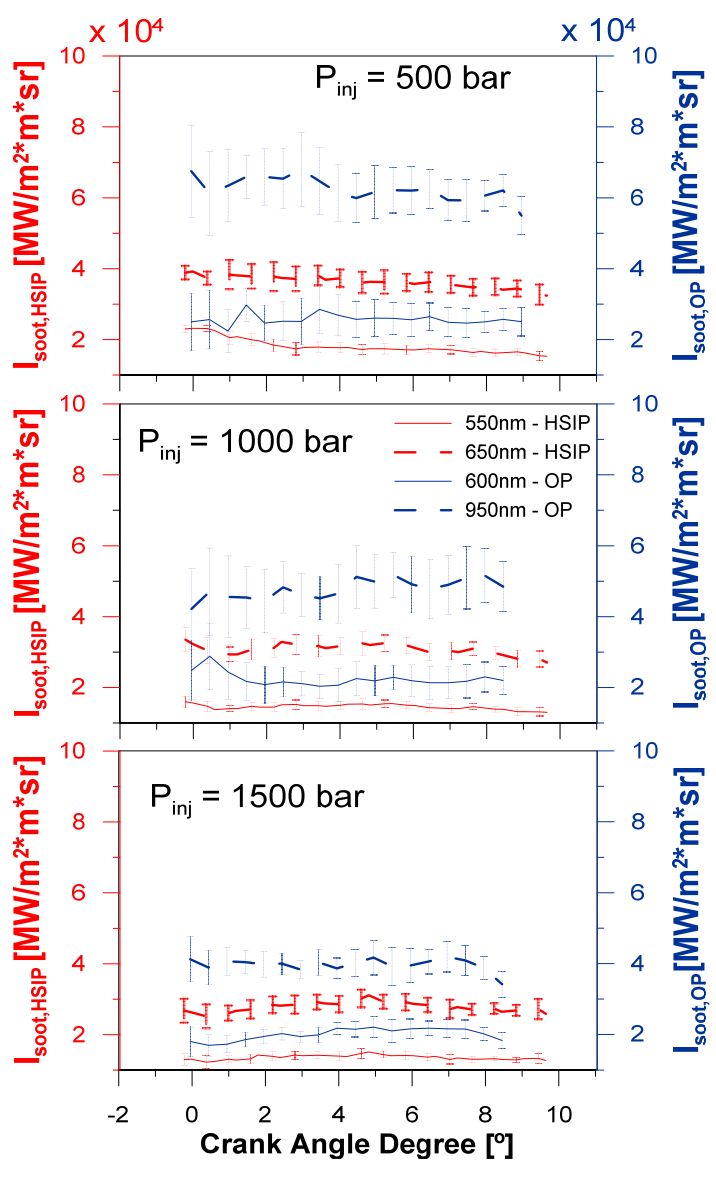

Figure 7. Temporal evolution of the spectral intensity using both measurement systems, HSIP and OP.

As was mentioned in methodology section, optoelectronic Pyrometer has a particular field of vision, which is smaller than the one acquired with High Speed Imaging Pyrometer. To ensure an appropriate comparison between both methods, the HSIP images are processed considering the particular vision field of the Optoelectronic Pyrometer as it is shown in the figure 8 .

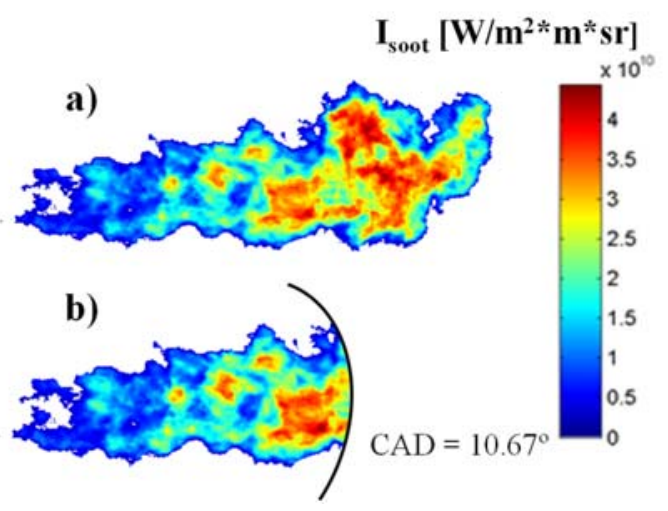

Figure 8. a) Raw image obtain from High Speed Imaging Pyrometer (not processed); b) Image post processing to 
compare properly spectral intensity between High Speed Imaging Pyrometer and Optoelectronic Pyrometer

Considering the effect of injection pressure, it is stated that the higher the injection pressure used, the lower spectral intensity is obtained. To provide further insight in this behavior, the maximum spectral intensity and its corresponding axial position from the injector orifice for the three different injection pressures tested and for two different wavelengths are shown in figure 9. This information is acquired from High Speed Imaging Pyrometer, which provides both, temporal and also spatial spectral intensity.

Independent of the wavelength used, the spectral peak intensity moves closer to the injector when the injection pressure is reduced. This behavior is due to shorter lift-off lengths are achieved when the injection pressure is reduced and consequently the soot volume fractions are increased [16][33]. In fact, when the injection pressure was varied, no significant changes in the mixture fraction field were attained, nevertheless, it is well-known that the lift-off length is reduced due to a different balance between flow and flame velocities [33].

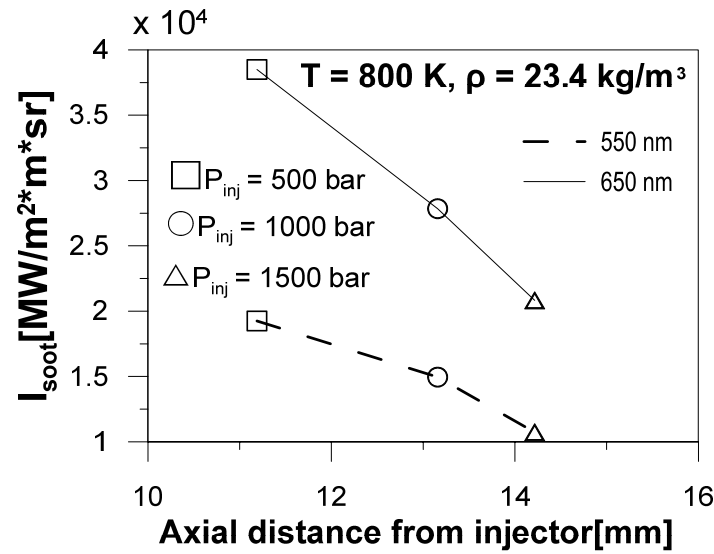

Figure 9. Maximum spectral intensity and its corresponding axial position from the injector orifice for the three different injection pressures in two different wavelengths

Figure 10 represents the maximum spectral intensity and its corresponding axial position from the injector orifice for the three different injection pressures, maintaining a constant wavelength $(550 \mathrm{~nm})$ and ambient density, $23.4 \mathrm{~kg} / \mathrm{m}^{3}$ for two ambient temperatures, $800 \mathrm{~K}$ and $900 \mathrm{~K}$. Thus, when the ambient temperature is increased, the axial position of the peak spectral intensity moves closer to the injector hole. This behavior implies a similar result as when the injection pressure is reduced, the lift-off length is shortened and therefore the amount of soot is increased as well as its radiance. In addition, two cases varying the ambient density have been also included. In these cases, density has been reduced up to 18.9 $\mathrm{kg} / \mathrm{m}^{3}$ for both ambient temperatures. Therefore, when density is decreased, the lift-off length moves farther from the injector hole and soot and spectral intensity are also reduced.

Page 8 of 17

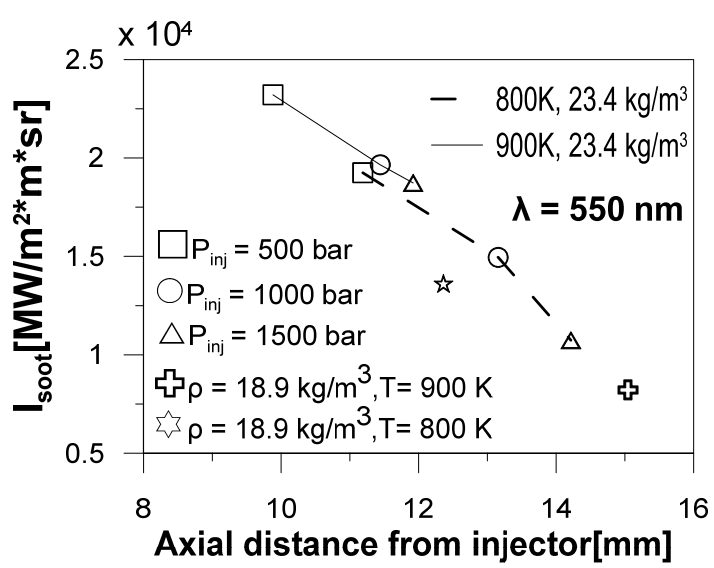

Figure 10. Maximum spectral intensity and its corresponding axial position from the injector orifice for the three different injection pressures, two ambient temperatures and two densities at the same wavelength

The temporal evolution of the soot temperature and optical thickness using equation (3) are presented along with the adiabatic flame temperature in figure 11. Adiabatic flame temperature is calculated with the assumption of constant pressure at each step of calculation, adiabatic burning of the stoichiometric fuels/air mixture and considering a conventional chemical equilibrium model, following the scheme proposed by Way [34]. All this information is presented for both optical systems especially the effect of injection pressure maintaining a constant ambient temperature of $900 \mathrm{~K}$ and density of $23.4 \mathrm{~kg} / \mathrm{m}^{3}$.

Independent of the optical system used, for the injection pressure sweep performed, the optical thickness has low values, from 0.2 up to almost 0.4 . Focusing on injection pressure effect, it could be stated that when the injection pressure is increased, the $\mathrm{KL}$ is reduced. This behavior has been explained considering figure 9. The lower the injection pressure, the shorter the lift-off length and the higher the soot.

The soot temperature values are lower than the adiabatic flame temperature, by around $350 \mathrm{~K}$, This observation agrees with soot thermometry studies reported in the literature for diesel engines [35]. Soot thermometry measures the soot temperature, which is not exactly equivalent to the flame temperature in particular for diffusion flames. This fact does not imply that soot radiation has no influence on the peak flame temperatures. Radiative cooling from soot can reduce the gas temperatures in the sooting area, which are coupled to the high temperature flame by conductive heat transfer. [35] 


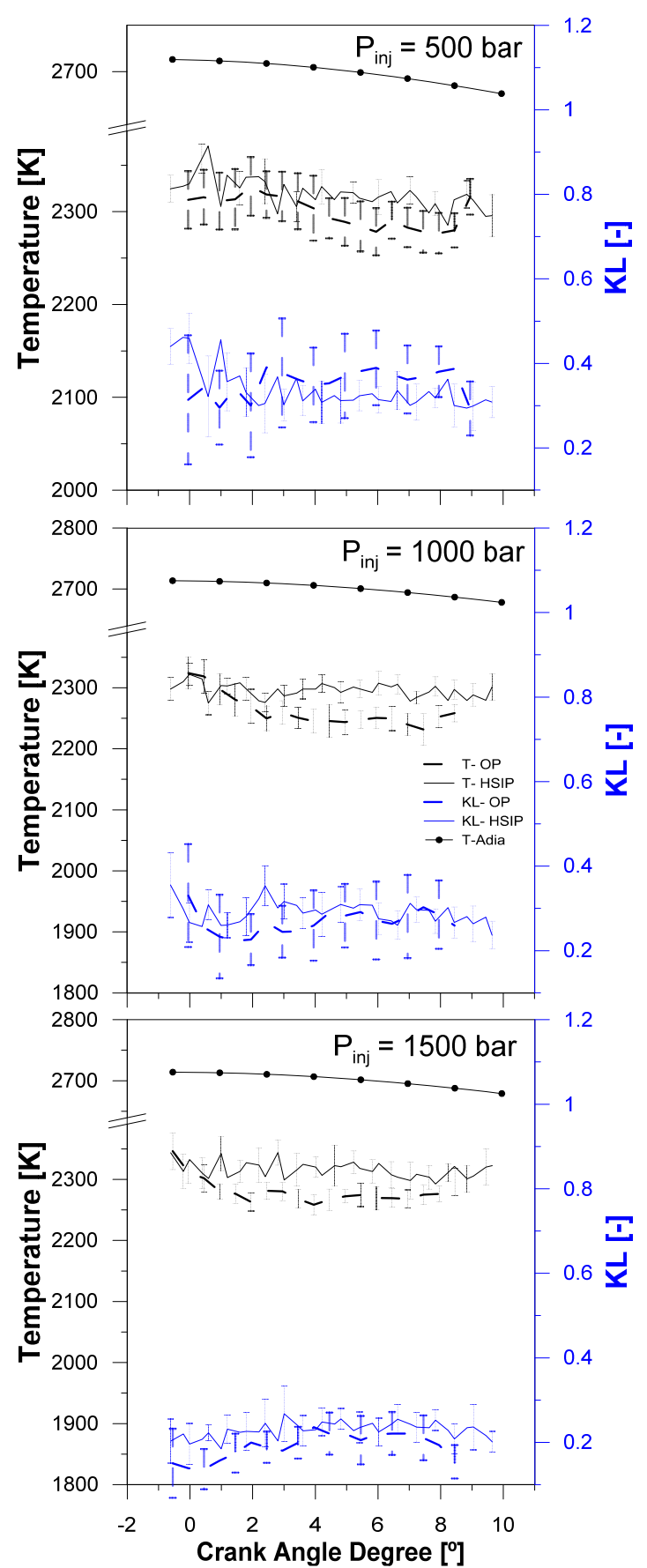

Figure 11. Temporal evolution of KL, soot temperature and adiabatic flame temperature for both measurement systems, three different injection pressures and constant ambient temperature and density.

Thus, soot temperature results for the three different injection pressures tested show quite similar values. This is because these operating conditions are low-radiation environments and consequently the impact of soot radiative heat transfer is similar and relatively minor for these particular conditions. Slight differences regarding optical thickness and overall soot temperature are found between both optical methods. It seems Page 9 of 17 to be an underestimation (around 20K) for the Optoelectronic Pyrometer. Nonetheless, considering the differences in terms of optical set-up between both methods, the variation in results are acceptable and consequently the optoelectronic pyrometer seems to provide accurate enough results.

\section{Radiant fraction}

Considering the local soot temperature and optical thickness correspond to a blackbody spectral intensity $\left(\mathrm{I}_{\mathrm{b}, \lambda}\right)$ and soot spectral emissivity $\left(\varepsilon_{\lambda}\right)$ at each instant, the total radiation in Joules, $Q_{\text {rad, }}$ is given by equation (5)

$$
Q_{\text {rad }}=\pi \int_{t} \int_{A} \int_{\lambda} \varepsilon_{\lambda} I_{b, \lambda} d \lambda d A d t
$$

Where $t$ represents the exposure time in which the optical system is registering flame luminosity, and $A$ is the flame area obtained by equation (6):

$$
A_{t}=2 \pi r \int_{x} d x
$$

Where $r$ is the flame radius, which is determined from a temporal image of the flame and $d x$, is the axial widths. In this case, the axial width corresponds with one pixel.

It is worthy to note that radiation is also emitted by $\mathrm{CO}_{2}$ and $\mathrm{H}_{2} \mathrm{O}$ molecules but it is concentrated in a narrow spectral bands and its magnitude is assumed to be much smaller than that of soot particles [11]. Thus, as in Musculus [35] and Skeen [13], the radiant fraction, $X_{\text {rad }}$, is defined as the fraction of the total chemical energy released during injection that is lost due to radiation heat transfer. This is expressed as:

$$
X_{\text {rad }}=Q_{\text {rad }} / m_{f} Q_{L H V}
$$

Where $m_{f}$ represents the mass of fuel injected and $Q_{L H V}$ is the lower heating value of 30\% Decane and 70\% Hexadecane $(43995 \mathrm{KJ} / \mathrm{Kg})$.

In figure 12 the radiant fraction results for the different operating conditions are presented. The lowest values of radiant fraction are found for $800 \mathrm{~K}$. Depending on the injection pressure, the results range from $0.011 \%$ up to $0.224 \%$. The higher the injection pressure, the lower the radiant fraction. For $900 \mathrm{~K}$ in-cylinder ambient temperature, the lowest radiant fraction is $0.084 \%$ and the largest is $0.340 \%$. The trend in terms of radiant fraction and considering the effect of injection pressure is similar between both ambient temperatures. In addition, when the ambient density is decreased the radiant fraction is also decreased. This behavior is more evident when the ambient temperature is lower. 


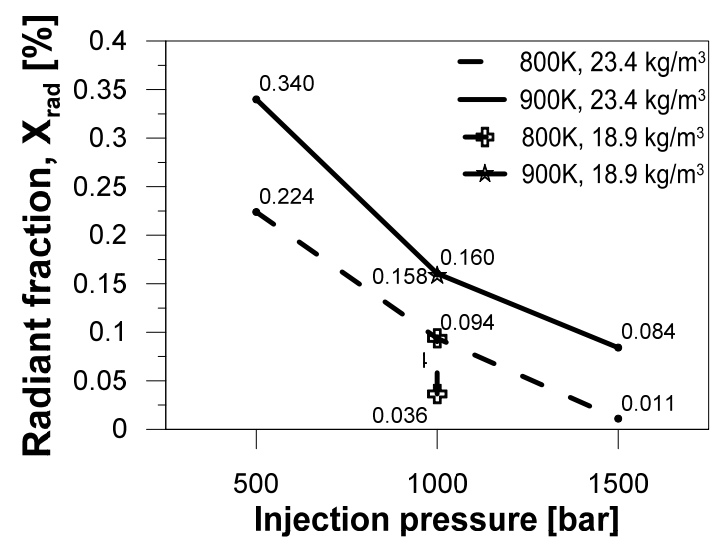

Figure 12. Radiant fraction considering different injection pressures, ambient temperatures and densities.

The flame radiation for a $2310 \mathrm{~K}$ blackbody having the same area as the case of $900 \mathrm{~K}$ (ambient temperature) and 500 bar (injection pressure) is calculated. The energy emitted from this blackbody over a $4.5-\mathrm{ms}$ time injection duration is approximately 16.3 Joules, representing a radiant fraction of $2.31 \%$. Thus, the maximum observed radiant fraction from the spectral data is approximately an order of magnitude less than that expected from a $2310 \mathrm{~K}$ blackbody having the same surface area and emitting over the full injection hydraulic period.

Comparing results with other radiant fraction studies, in particular Skeen [13] has presented results in a combustion vessel using an injector with single hole nozzle of $90 \mu \mathrm{m}$ nominal diameter, $\mathrm{n}$-dodecane as fuel under ECN spray conditions $\left(1500\right.$ bar; $\left.\mathrm{X}_{\mathrm{O} 2}=15 \% ; \rho=22.8 \mathrm{~kg} / \mathrm{m}^{3}\right)$ and sweeping the ambient temperature. Thus, some operating conditions are quite similar to the ones presented in this research. For the conditions of Skeen's research, at $850 \mathrm{~K}$ ambient temperature the radiant fraction is $0.007 \%$ and at $900 \mathrm{~K}$ is $0.068 \%$. Thus, results are on the same order of magnitude compared with the obtained in the present work. In particular, when higher injection pressure is used, the results presented in this study are similar to the ones presented by Skeen. Taking into account the significant differences in the experimental procedure, it is remarkable that there is consistency between the present work and the research performed by Skeen.

In addition, it is interesting to underline that alkane blends use will imply a lower soot production compared with a real diesel fuel which should contains some aromatic compounds. Therefore some slight underestimation in terms of radiant fraction is attained, although trends are completely valid.

\section{Characterization of radiation in a Four Stroke Diesel Engine}

In this section, the Optoelectronic Pyrometer is used to evaluate the radiant fraction in a production multi-cylinder engine.

\section{In-cylinder radiation intensity and Rate of Heat Released}

In figure 13 an example of the raw data obtained with the Optoelectronic Pyrometer is presented. The temporal evolution of the spectral intensity $\left(\mathrm{MW} / \mathrm{m}^{2} \mathrm{sr}\right)$ at both wavelengths, $600 \mathrm{~nm}$ and $950 \mathrm{~nm}$ is shown for the $2000 \mathrm{rpm}$ and 5 bar BMEP case. Each curve represents the average and the standard deviation of 100 cycles recorded. Thus, under real conditions the results dispersion is higher than the shown in figure 7 for the optically accessible engine. This behavior is mainly due to skip fire mode provides more control over thermodynamic conditions and therefore lower dispersion.

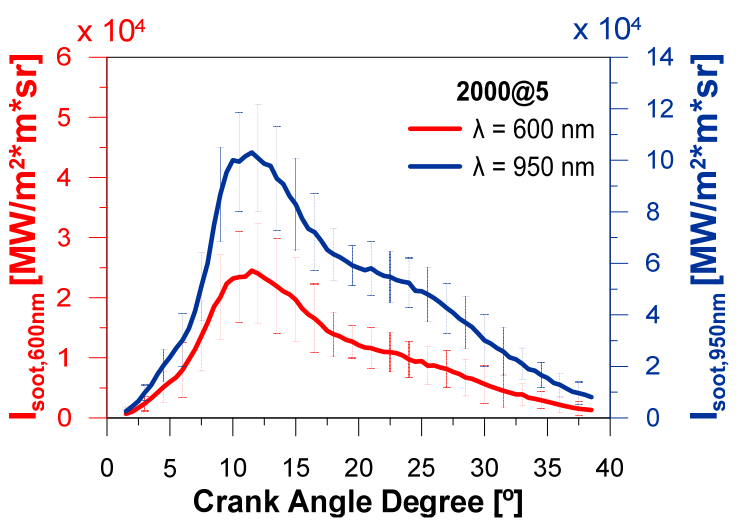

Figure 13. Temporal evolution of the spectral intensity using Optoelectronic Pyrometer at 2000 rpm and 5 bar BMEP.

In figure 14 temporal evolution of the RoHR and the radiation intensity $\left(\mathrm{MW} / \mathrm{m}^{2}\right)$ are presented. It should be noted that radiation intensity is the spectral intensity integrated from $300 \mathrm{~nm}$ up to $3000 \mathrm{~nm}$. Thus, each curve represents the average of 100 cycles recorded. Only the standard deviation for the radiation intensity is considered. RoHR dispersion is completely negligible and therefore only its average value is shown.

In general, it is possible to state that there are clear differences in radiation intensity profiles considering engine speed and overall load. Nevertheless, there is also some similarity in the temporal evolution of the different radiation intensity traces, for the same engine speed, shape and slopes are quite similar although the peak is different and higher when the load is increased. The range of the peak values varies from 0.15 $\mathrm{MW} / \mathrm{m}^{2}$ up to $1.8 \mathrm{MW} / \mathrm{m}^{2}$. 
Considering 1500 rpm results, 14 bar BMEP case shows higher maximum peak of radiation intensity compared to 8 bar BMEP. The lower load case has a more rapid rise rate. This behavior indicates that the soot radiant emissions in the diffusion burn phase depends on engine load and it seems to be faster when the load is lower. Similar results are obtained by Struwe [10].

For the $2000 \mathrm{rpm}$ cases, there is an important difference in terms of the magnitude of the radiant emission directly related with the loads used, 2 and 5 bar BMEP. In these cases of low load, it is interesting to note changes in the slope of radiation emission during the end of the combustion process where the late combustion diffusion is attained. In this part of the combustion process, the amount of soot is increased and therefore the radiation emission is increased as well.

Comparing cases with constant engine load and different engine speed, ( $3000 \mathrm{rpm}$ versus $2500 \mathrm{rpm}$ ) similarity between both radiation intensity profiles can be observed. This fact implies that engine speed has a secondary impact on engine radiation.

Considering the injection strategy proposed for all tested cases, pilot and main injection, the amount of premixed phase in the RoHR is reduced. In general, the radiation intensity starts with the RoHR and the maximum peak intensity of both profiles are almost coincident. The radiation traces end at similar crank angle degree as the RoHR.

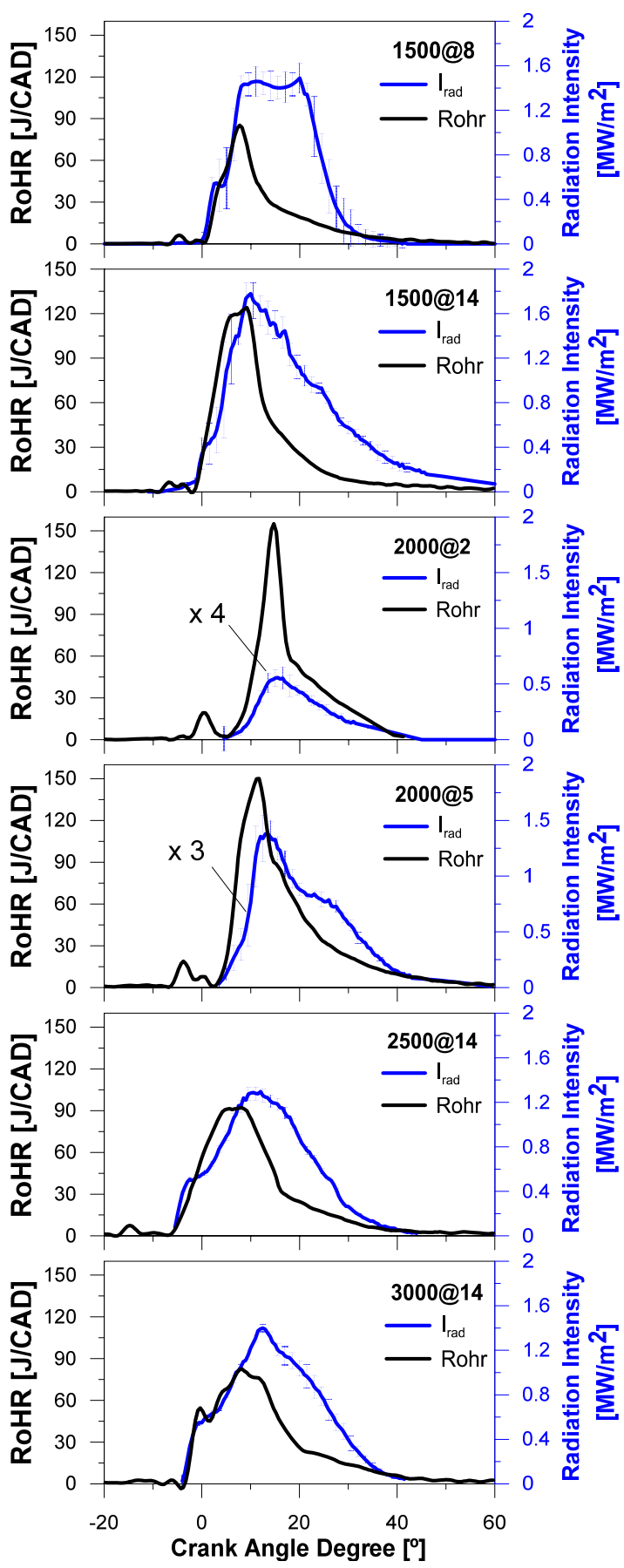

Figure 14. Radiation intensity and RoHR for the six different operating conditions tested

\section{In-cylinder soot temperature and KL}

Figure 15 shows the temporal evolution of injection rate, soot temperature and optical thickness KL. As in previous figures, the curves are representing the average and standard deviation of 100 cycles. Injection rate profile is simulated from a particular sub-model included in CALMEC [23] which has 
been calibrated to the injector and nozzle used in the present research.

Analyzing the profiles on a time resolved basis, it could be stated that KL profiles show great similarity with radiation intensity traces, which are presented in figure 14 . When the injection process ends, a sudden decrease in KL signal is obtained. The maximum peak of the optical thickness traces almost coincides with the end of injection. After the end of injection, the oxidation process governs soot emissions and therefore the soot formation has arrived at its maximum value [36] The 2 bar BMEP case, doesn't follow this behavior.

Keeping constant engine speed (1500 rpm or $2000 \mathrm{rpm}$ cases), when the load is increased the soot formation was also increased. This behavior was shown even considering other cross effects. For instance, in the $1500 \mathrm{rpm}$ cases, EGR can also be considered constant for both loads tested ( 8 and 14 bar $\mathrm{BMEP})$. By contrast, the injection pressure is higher when the load is increased (table 5), and therefore reduced soot formation could be expected. Nevertheless, considering incylinder measurements, the effect of higher equivalence ratio due to higher load seems to govern the total soot formation and consequently, higher equivalence ratio provides higher soot formation.

For the case of $2000 \mathrm{rpm}$ the evidences is even more noticeable. In this case, two loads (2 and 5 bar BMEP) were tested. The 5 bar BMEP case had lower EGR and higher injection pressure, consequently, lower soot formation is expected. Contrarily, higher soot formation is obtained, this is also mainly due to a higher equivalence ratio. Significant decrease in soot temperature is observed when EGR is increased. Moreover, soot temperature values are consistent with other works in similar conditions $[10,35]$

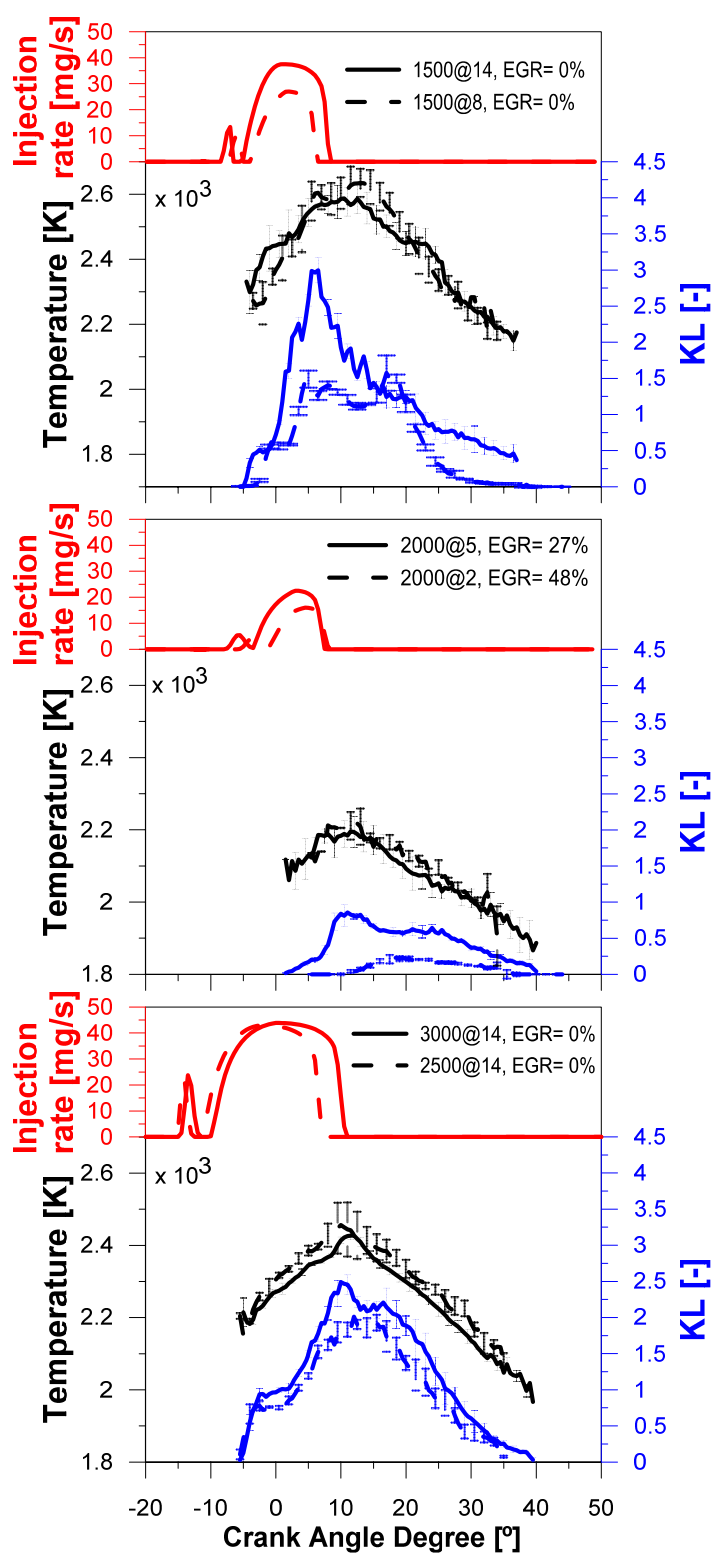

Figure 15. Temporal evolution of $K L$, soot temperature and injection rate for the six different operating conditions tested.

\section{Energy balance considering radiant fraction}

As in previous section, the total radiation was calculated with equation (5) using the local soot temperature and optical thickness corresponding to a blackbody spectral intensity $\left(\mathrm{i}_{\mathrm{b}, \lambda}\right)$ and soot spectral emissivity $\left(\varepsilon_{\lambda}\right)$ at each instant.

In these cases, there was no visual information to calculate flame area. Therefore, the temporal evolution of natural luminosity obtained in a transparent engine with similar bowl and cylinder geometry as the light duty engine used in this research work was used [37]. The flame area starts with the first spots of flame luminosity and reaches a constant value 
during the diffusion combustion which is similar to the bowl area. Finally, the area is zero when the luminosity ends.

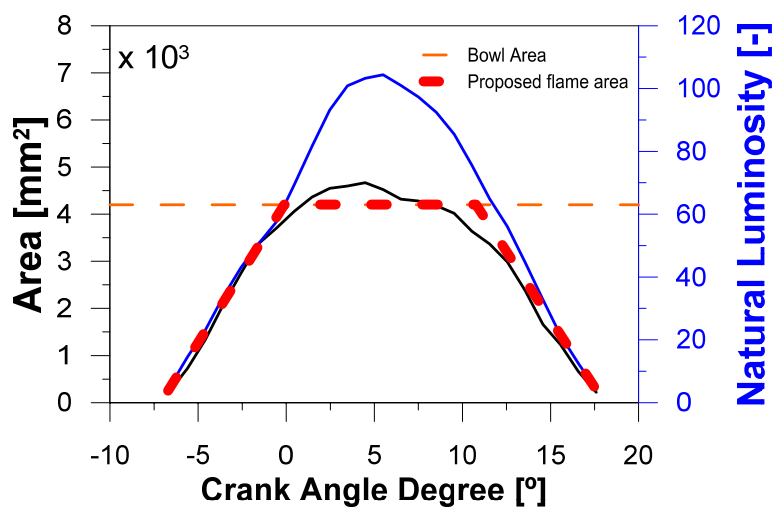

Figure 16 Temporal evolution of flame area and natural luminosity for an optical engine with similar bowl geometry and operating condition than the used in the current research.

In order to quantify the total radiation in the real multicylinder engine, the temporal evolution of the flame area proposed for each case is defined as a constant value during the quasi steady diffusion combustion which corresponds with the bowl area, starting and finishing according to the spectral intensity signal. Similar assumption was used by Musculus [33]

Figure 17 presents the radiant fraction for the different operating conditions tested. Results show some discrepancies concerning load effect on radiation intensity if they are compared with figure 14. These differences can be attributed to the flame area calculation. Nevertheless, considering literature $[10,38]$ seems that values obtained are completely reasonable although more effort should be done to better characterize the flame area.

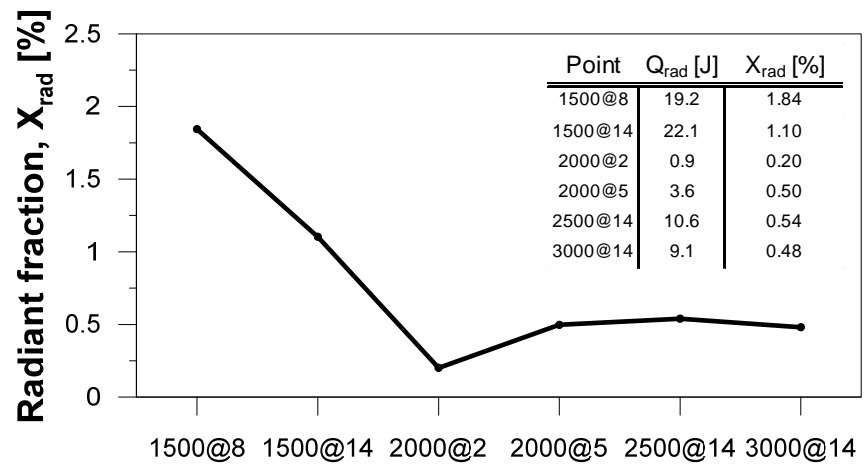

\section{Figure 17. Radiant fraction for the six different operating conditions tested.}

To provide general vision of how energy is split, the global energy balance (GEB) methodology developed by Payri et al. has been applied [36] to the studied engine operating conditions. With the instantaneous in-cylinder pressure as the main input, the methodology is able to detail the energy distribution in the engine, describing the different paths thanks to specific sub-models, accounting for all the relevant subsystems. Figure 18 shows GEB in relative terms compared with the total amount of chemical fuel energy. For each operating point, the internal split of energy is evaluated. The terms considered are the net indicated power $\left(\dot{N}_{i, n e t}\right)$, the heat transfer (HT) to the chamber walls including convection $\left(\dot{Q}_{\text {cham,conv }}\right)$ and radiation $\left(\dot{Q}_{\text {cham }, \mathrm{rad}}\right)$, HT to the ports walls ( $\left.\dot{Q}_{\text {ports }}\right)$, the enthalpy flow of the exhaust gases at the turbine inlet $\left(H_{g}\right)$ and finally the unbalance term, $\dot{Q}_{m i s c}$ due to the experimental and modeling uncertainties.

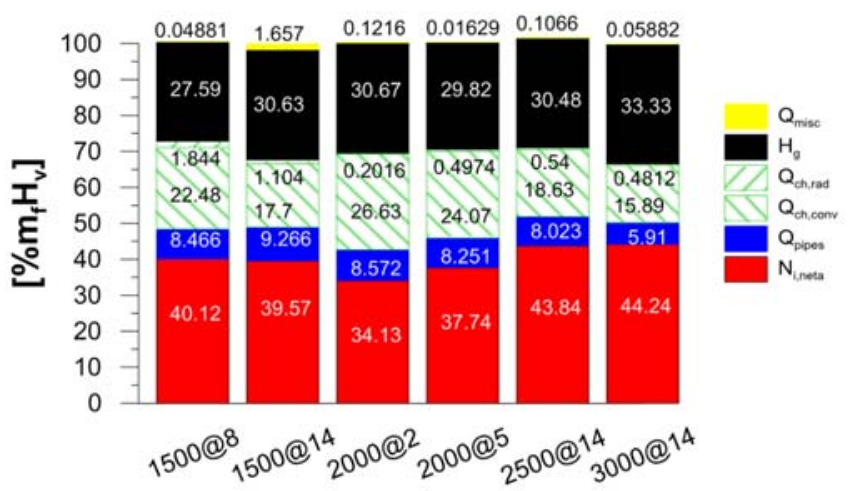

Figure 18. Internal GEB at different operating conditions

Indicated engine efficiency range depends on load and engine speed. In the analyzed operating conditions, it ranges from $34 \%$ for the case with the lowest load up to $44 \%$ at the highest load and speed tested.

The chemical energy which is not converted into mechanical power delivered to the piston or heat transfer to the chamber walls is lost as heat rejection to the ports (mainly in the exhaust ones) and the enthalpy to the exhaust gases. It can be seen that the relative weight of the heat transfer to the ports is about one third to one half of the heat transfer in the chamber, while the value of the exhaust enthalpy does not show a dramatic variation.

In global terms, the weight of HT to the chamber walls tends to diminish with the load and speed. Regarding the HT split between radiation and convection, it can be stated that the radiation is more sensitive to the operating conditions than convection. Thus, the convective heat transfer ranges in figure 18 from $16 \%$ to $27 \%$ of the fuel energy in all the analyzed operating conditions (maximum ratio of 1.65) while the radiation varies from $0.2 \%$ to $1.8 \%$ in the same figure (maximum ratio of 9). Finally, taking into account the relative weight between radiation/convection, it can be concluded that the radiation is clearly lower than convection. This can be better seen in figure 19, where the percentage of radiation in the total chamber heat losses (including convection and radiation) is shown. As can be seen, the values range from

Page 13 of 17 
about $0.7 \%$ to $7.6 \%$ in the different studied cases, showing a qualitative trend very similar to that of the radiant fraction plotted in figure 17.

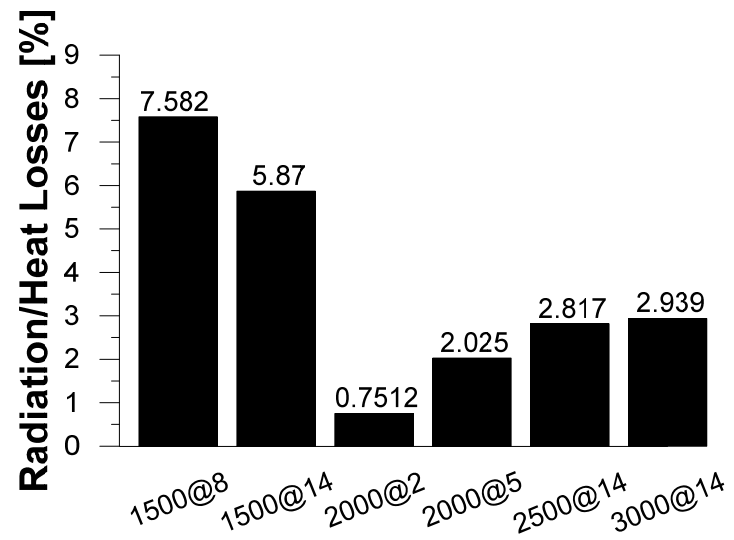

Figure 19. Percentage of radiation in the heat losses for the different studied cases.

\section{SUMMARY/CONCLUSIONS}

The presented research evaluates the amount of energy lost to soot radiation relative to the input fuel chemical energy during the combustion event under different operating conditions. An optical accessible engine and a real production engine have been used to characterize experimentally this phenomenon. In particular, two color method has been applied by means of high speed imaging and a dedicated optoelectronic pyrometer. Thus, soot temperature and optical thickness have been used to estimate the total radiation and the radiant fraction.

Considering results obtained under simplified and controlled conditions the following conclusions can be stated:

- In spite of several assumptions while analyzing data from the Optoelectronic Pyrometer, information of combustion process is spatially integrated along the line of the probe sight, it provides similar results in terms of soot temperature and optical thickness (KL) compared with a conventional high speed imaging pyrometer.

- An increase in the spectral intensity is obtained when the injection pressure is decreased and/or the ambient temperature and density are increased. This behavior is mainly due to a shorter lift-off lengths which implies a higher soot volume fractions.

- Radiant fraction of the different operating conditions tested show values from $0.011 \%$ up to $0.224 \%$ depending on the injection pressure at $800 \mathrm{~K}$. The higher the injection pressure, the lower the radiant fraction. For the cases of $900 \mathrm{~K}$, the lowest radiant fraction is $0.084 \%$ and the largest is $0.340 \%$. Slight differences have been obtained when the ambient density is varied. Thus, the radiant fraction decreases when density decreases. This behavior seems to be more evident when the ambient temperature is lower. These values are around an order of magnitude lower than a blackbody with the same area radiating during the whole injection event. In general the values obtained present consistency with the work performed by Skeen [13].

The main conclusion from the multi-cylinder production engine study are summarized as follows:

- Considering temporal evolution of radiation traces, it is possible to state that shape and slopes are similar interdependent of the cases studied, although the peak is different and clearly higher when the load is increased. In addition, it is also demonstrated that engine speed provides a secondary impact on engine radiation. The range of the radiation peak values obtained comes from $0.8 \mathrm{MW} / \mathrm{m}^{2}$ up to $1.8 \mathrm{MW} / \mathrm{m}^{2}$. These results are consistent with the other authors who have tested similar engines under similar operating conditions.

- In-cylinder soot temperature and optical thickness (KL) have been characterized under different engine conditions. The range of the KL peak values obtained comes from 0.2 for low load conditions up to almost 3 for the highest load case. In terms of soot temperature, the range goes from $2200 \mathrm{~K}$ up to $2600 \mathrm{~K}$. Thus, KL profiles present similarity with radiation intensity curves and seems to be governed by the diffusion combustion. In particular, when the injection process ends, the soot formation decays rapidly. Concerning soot temperature, the expected effect of EGR is observed. When the intake oxygen concentration is decreased due to EGR, the soot temperature is also diminished.

- Radiation fraction has a low weight in the total energy balance of the engine, ranging from $0.2 \%$ to $1.8 \%$ of the fuel energy in the different studied cases. Hence, it is lower than the heat transfer in the ports and much lower than the convective heat transfer in the chamber. If the relative weight in the total heat transfer in the chamber is analyzed, it can be concluded that only $0.7 \%$ to $7.6 \%$ is due to radiation. No clear trend can be observed with the load and engine speed, probably due to the uncertainties in the flame area determination and the fact that the original engine cartography was used, and thus the effect of some variables that can be 
important for the soot formation and radiation (such as EGR rate) are not kept constant.

\section{REFERENCES}

1. Caresana, F., Bilancia, M., Bartolini C.M., "Numerical method for assessing the potential of smart engine thermal management: Application to a medium-upper segment passenger car", Appl. Therm. Eng. 31(16), 3559-3568, 2011, doi:10.1016/j.applthermaleng.2011.07.017.

2. Chalgren, R. and Allen, D., "Light Duty Diesel Advanced Thermal Management," SAE Technical Paper 2005-01-2020, 2005, doi:10.4271/2005-01$\underline{2020}$.

3. Dimopoulos, P., Bacha, C., Soltica, P., Boulouchos, K., "Hydrogen-natural gas blends fuelling passenger car engines: Combustion, emissions and well-towheels assessment", Int. J. Hydrogen Energ. 33(23), 7224-7236,2008, doi:10.1016/j.ijhydene.2008.07.012.

4. Osada, H., Uchida, N., Shimada, K., and Aoyagi, Y., "Reexamination of Multiple Fuel Injections for Improving the Thermal Efficiency of a Heavy-Duty Diesel Engine," SAE Technical Paper 2013-01-0909, 2013, doi:10.4271/2013-01-0909.

5. Sanli, A., Ozsezen A.N., Kilicaslan, I., Canakci, M., "The influence of engine speed and load on the heat transfer between gases and in-cylinder walls at fired and motored conditions of an IDI diesel engine",", Appl. Therm. Eng. 28(11-12),1395-1404, 2008, doi:10.1016/j.applthermaleng.2007.10.005.

6. Taymaz, i., "An experimental study of energy balance in low heat rejection diesel engine", Energy 31 (2-3) 364-371 2006, doi:10.1016/j.energy.2005.02.004.

7. Morawitz, U., Mehring, J., and Schramm, L., "Benefits of Thermal Spray Coatings in Internal Combustion Engines, with Specific View on Friction Reduction and Thermal Management," SAE Technical Paper 2013-01-0292, 2013, doi: 10.4271/2013-01-0292.

8. Serrano, J., Olmeda, P., Tiseira, A., García-Cuevas, L. et al., "Importance of Mechanical Losses Modeling in the Performance Prediction of Radial Turbochargers under Pulsating Flow Conditions," SAE Int. J. Engines 6(2):729-738, 2013, doi:10.4271/2013-01-0577.

9. Benajes, J. et al., "Analysis of the combustion process, pollutant emissions and efficiency of an innovative 2-stroke HSDI engine designed for automotive applications", Appl. Therm. Eng., 58(12), 181-193, doi:10.1016/j.applthermaleng.2013.03.050.
10. Struwe, F.J., "In-cylinder Measurement of Particulate Radiant Heat Transfer in a Direct Injection Diesel Engine" SAE Technical Paper 2003-01-0072, 2003

11. Furmanski P., Banaszek J. and Wisniewski T. S., "Radiation Heat Tranfer in a Combustion Chamber of Diesel Engine with Partially Transparent Burnt Gas Zone”. SAE Technical Paper 980504, 1998.

12. Vogelin P., "Experimental investigation of multi-incylinder pyrometer measurements and exhaust soot emissions under steady and transient operaton of a heavy-duty Diesel engine". SAE Technical Paper 131ICE-0145, 2013.

13. Skeen S., Manin J. and Pickett L., "Quantitative Spatially Resolved Measurements of Total Radiation in High-Pressure Spray Flames”. SAE Technical Paper 2014-01-1252, 2014.

14. Flynn, P., Mizusawa, M., Uyehara, O., and Myers, P., "An Experimental Determination of the Instantaneous Potential Radiant Heat Transfer Within an Operating Diesel Engine," SAE Technical Paper 720022, 1972, doi:10.4271/720022.

15. Li, X, and Wallace, J.S., "In-Cylinder Measurement of Temperature and Soot Concentration Using the Two-Color Method," SAE Paper No.

16. Tree, D.R, Svensson, K. I., "Soot processes in compression ignition engines". Progress in Energy and Combustion Science 33 (2007) 272-309

17. Zhao, H.C., and Broughton, F. P., "Determination of True Temperature and Total Radiation From Luminous Gas Flames," Ind. Eng. Chem. Anal. Ed., 4(2), pp. 166-175, 1932, doi:10.1021/ac50078a004

18. Vattulainen, J., Nummela, V., Hernberg, R. and Kytölä, J., "A system for quantitative imaging diagnostics and its application to pyrometric incylinder flame-temperature measurements in large diesel engines", Meas. Sci. Technol., Vol. 11 Nr. 2, 2000 doi:10.1088/0957-0233/11/2/303

19. Musculus, P.B. M., Singh, S. and Reitz, R. D., "Gradient effects on two-color soot optical pyrometry in a heavy-duty DI diesel engine", Combustion and Flame,153,216-227,2008, doi:10.1016/j.combustflame.2007.10.023

20. Pastor J.V., Garcia J.M., Pastor J. M., Buitrago J.E., "Analysis Methodology of Diesel Combustion by Using Flame Luminosity, Two-Colour Method and Laser-Induced Incandescence". SAE Technical Paper 2005-24-012, 2005.

21. DRIVVEN Stand Alone Direct Injector Driver System User's Manual October 2010. Drivven, INC. 12001 Network Blvd, 110. San Antonio, Texas 78249. Web: www.drivven.com $<$ http://www.drivven.com $>$

22. Payri F., Pablo Olmeda P., Martin J., Carreño R., “A New Tool to Perform Global Energy Balances in DI Diesel Engines". SAE Technical Paper 2014-010665, 2014.

23. F. Payri, S. Molina, J. Martín, O. Armas, Influence of measurement errors and estimated parameters on 
combustion diagnosis, Appl. Therm. Eng. 26 (2e3) (2006)226e236, http://dx.doi.org/10.1016/j.applthermaleng.2005.05.0 06.

24. Payri F., Olmeda P., Martín J., García A., “A complete $0 \mathrm{D}$ thermodynamic predictive model for direct injection diesel engines", Appl. Energy 88 (12) (2011)4632e4641,http://dx.doi.org/10.1016/j.apenerg y.2011.06.005.

25. Payri F., Galindo J., Martín J., Arnau F.J., "A Simple Model for Predicting the Trapped Mass in a DI Diesel Engine". SAE Technical Paper Series 200701-0494, 2007.

26. Lapuerta M., Armas O., Hernandez J.J., "Diagnosis of DI diesel combustion from in-cylinder pressure signal by estimation of mean thermodynamic properties of the gas". Appl. Therm. Eng. 19 (5) (1999) 513-529, http://dx.doi.org/ 10.1016/S13594311(98) 00075e1.

27. Payri F., Margot X., Gil A., Martín J., "Computational Study of Heat Transfer to the Walls of a DI Diesel Engine". SAE paper 2005-01-0210, 2005.

28. Benajes J., Olmeda P., Martín J., Carreño R., “A new methodology for uncertainties characterization in combustion diagnosis and thermodynamic modelling". Appl. Therm. Eng. 71 (2014) 389-399. http://dx.doi.org/10.1016/j.applthermaleng.2014.07.0 10.

29. Payri F., Pastor J., Garcia J., Measurement Science and Technology, vol. 18, no. 8, pp. 2579-2598, 2007.

30. Zhao H. and Ladommatos N, Progress in Energy and Combustion Science, vol. 24, no. 3, pp. 221-255, 1998.

31. Hottel H. and Broughton F., Industrial and Engineering Chemistry, vol. 4, no. 2, pp. 166-175, 1932.

32. "Operating Manual Product and Guide". Optical probe's manual.

33. Pickett L.M. and Siebers D.L., "Soot in diesel fuel jets: effects of ambient temperature, ambient density, and injection pressure". Combustion and Flame 138 (2004) 114-135.

34. Way RJB. "Methods for determination of composition and thermodynamic properties of combustion products for internal combustion engine calculations". P I Mech Eng 1976;190:686e97.

35. Musculus, P.B. M., "Measuremets of the influence of Soot Radiation on In-Cylinder Tempratures and Exhaust NOx in a Heavy-Duty DI Diesel Engine”. . SAE Technical Paper 2005-01-0925, 2005.

36. Arrègle J., Pastor J.V., López J.J., García A.,"Insights on postinjection-associated soot emissions in direct injection diesel engines". Combustion and Flame 154 (2008) 448-461.

37. Lopez J.J., García-Oliver J.M., García, A., Domenech V., "Gasoline effects on spray characteristics, mixing and auto-ignition processes in a $\mathrm{CI}$ engine under
Partially Premixed Combustion conditions". Applied Thermal Engineering 70 (2014) 996-1006.

38. Manin J., Pickett L.M., Skeen S., " Two-Color Diffused Back-Illumination Imaging as a Diagnosticfor Time-Resolved Soot Measurements in Reacting Sprays". SAE Technical Paper 2013-012548, 2013.

\section{CONTACT INFORMATION}

Dr. Antonio García

CMT - Motores Térmicos /Universitat Politècnica de València angarma8@mot.upv.es

\section{ACKNOWLEDGMENTS}

The authors would like to thank General Motors for supporting this research. 
DEFINITIONS/ABBREVIATIONS

BMEP

CA

CMOS

$\mathrm{CO}_{2}$

DI

ECN

EGR

EVC

FWHM

GHG

HSIP

HT

$\mathbf{I}, \boldsymbol{\lambda}$

ICE

Isoot
Brake Mean Effective

Pressure

Crank Angle

Complementary Metal

Oxide Semiconductor

Carbon Dioxide

Direct Injection

Engine Combustion

Network

Exhaust Gases

Recirculation

Exhaust Valve Close

Full Width at Half

Maximum

GreenHouse Gas

High Speed Imaging

Pyrometer

Heat Transfer

Spectral Intensity of Black Body

Internal Combustion

Engines

Spectral Intensity
IVC

KL

$\mathbf{K}_{\mathrm{s}}$

$\mathbf{m}_{\mathrm{f}}$

OP

Pinj

LHV

RoHR

SoI

SoE

TDC

VGT

$\mathrm{X}_{\mathrm{O} 2}$

$\boldsymbol{\alpha}$

$\boldsymbol{\varepsilon} \lambda$

$\lambda$

$\rho$

$\Omega$
Inlet Valve Close

Optical Thickness

Conical Shape

Mass of Fuel Injected

Optoelectronic

Pyrometer

Injection Pressure

Lower Heating Value

Heat Release Rate

Start of Injection

Start of Energizing

Top Dead Center

Variable Geometry

Turbocharger

Oxygen Fraction

Absorptivity Coefficient

Spectral Emissivity

Wavelenght

Density

Solid Angle 